\title{
Remifentanil patient-controlled analgesia for labor - monitoring of newborn heart rate, blood pressure and oxygen saturation during the first 24 hours after delivery
}

\author{
Halina Konefat', Brygida Jaskott', Maria Beata Czeszyńska, Joanna Pastuszka²
}

1Department of Neonatology, Pomeranian Medical University, Szczecin, Poland 2Department of Anesthesiology and Intensive Therapy, Pomeranian Medical University, Szczecin, Poland

Submitted: 15 September 2011

Accepted: 8 February 2012

Arch Med Sci 2013; 9, 4: 697-702

DOI: 10.5114/aoms.2012.31306

Copyright @ 2013 Termedia \& Banach

\begin{abstract}
Introduction: There is no available information about the effects of remifentanil labor analgesia on newborns' vital signs in the first hours after delivery. The aim of the study was to assess changes in the heart rate, blood pressure and oxygen saturation during the first $24 \mathrm{~h}$ of neonatal life after using remifentanil patient-controlled analgesia (PCA) for labor analgesia.

Material and methods: Forty-four full-term neonates, 23 from intravenous PCA remifentanil labor anesthesia $0.2 \mu \mathrm{g} / \mathrm{kg}$, repeated not more frequently than every $2 \mathrm{~min}$, and 21 born to mothers without any pharmacological forms of analgesia, were studied. Heart rate, oxygen saturation, and systolic (SBP) and diastolic blood pressure (DBP) were monitored using a Nellcor Oxi Max monitor N5500 (Tyco Healthcare), and recorded at $1 \mathrm{~h}, 6 \mathrm{~h}, 12 \mathrm{~h}$ and $24 \mathrm{~h}$.

Results: No significant differences in heart rate $(p=0.54 ; p=0.26 ; p=0.60$; $p=0.83)$, oxygen saturation $(p=0.21 ; p=0.27 ; p=0.61 ; p=0.9)$ and $\operatorname{DBP}(p=0.98$; $p=0.31 ; p=0.83 ; p=0.58$ ) between the groups at $1 \mathrm{~h}, 6 \mathrm{~h}, 12 \mathrm{~h}$ and $24 \mathrm{~h}$. Newborns from the remifentanil group had lower SBP at $1 \mathrm{~h}$ of life $(59 \mathrm{~mm} \mathrm{Hg}$ vs. $68.5 \mathrm{~mm} \mathrm{Hg}$ ) but the difference was just on the borderline of statistical significance $(p>0.06)$. There were no significant differences in SBP between the groups at $6 \mathrm{~h}(p=0.65), 12 \mathrm{~h}(p=0.11)$, and $24 \mathrm{~h}(p=0.89)$ of life.

Conclusions: Remifentanil PCA analgesia during labor does not significantly modify the oxygen saturation, heart rate and blood pressure in infants during the first day of their life. Therefore, further studies are needed to explain the observed trend for arterial hypotension in the first hour of life in infants born to mothers treated with remifentanil.
\end{abstract}

Key words: labor pain, opioids, neonatal outcome.

\section{Introduction}

Remifentanil is a rapid-acting synthetic $\mu$-opioid receptor agonist with a very short half-life, that is quickly metabolized by plasma and tissue esterases, regardless of any hepatic or renal impairment, or age-related differences in half-life [1-3].

For a decade, anesthesiologists have used the unique properties of remifentanil in the settings of surgical anesthesia, sedation and postoperative analgesia since its introduction into labor analgesia. However,

\section{Corresponding author:}

Prof. Maria Beata Czeszyńska Department of Neonatology Pomeranian Medical University 2 Siedlecka St 72-010 Police Szczecin, Poland Phone/fax: +48 914253891 E-mail: beataces@ sci.pam.szczecin.pl 
remifentanil is not licensed to be administered to pregnant women. As it stands remifentanil is the best opioid for obstetric use so far. Proper informed consent, appropriate monitoring of the mother and the newborn, one-to-one nursing or midwifery care, as well as the availability of an attending physician experienced in neonatal resuscitation and an anesthesiologist with experience in the use of remifentanil, are important to ensure that this method retains its credit for obstetric analgesia [4].

Remifentanil rapidly and extensively crosses the placenta (umbilical vein/maternal artery ratio 0.88) in term pregnancies [5]. It is believed that although remifentanil crosses the placenta, it is eliminated quickly in neonates by rapid metabolism or redistribution. However, because of different duration of labor, pain severity and subjective feeling, total doses of remifentanil transferred during patient-controlled analgesia to the fetus/newborn may differ significantly. The phenomenon of the individual sensitivity to the drug and accumulation in some patients should also be taken into consideration. In general, the pharmacokinetics of opioids during fetal life and in newborns is guided by maturational aspects of absorption, distribution, metabolism and elimination of these drugs. In this age range, important factors such as gestational age, body composition, weight, liver maturation and impaired renal function result in considerable individual variability in the pharmacokinetics of the majority of drugs $[6,7]$.

There are limited studies about the safety of remifentanil use as a bolus in induction of general anesthesia for caesarean delivery [8-11]. In very few studies maternal and neonatal side-effects of remifentanil patient-controlled analgesia in labor are described [4, 11-14]. Cardiovascular instability and respiratory depression immediately after birth were noticed in some cases. In papers published up to now only Apgar score results, umbilical blood gas analysis or muscle rigidity during the first $10 \mathrm{~min}$ after birth were used as indicators of newborn wellbeing after remifentanil labor analgesia. In one study performed by Draisci et al., neonates were observed in the nursery with $\mathrm{SpO}_{2}$ monitoring removed at $3 \mathrm{~h}$ after birth [11]. None of the papers reports monitoring of the heart rate, oxygen saturation and blood pressure performed for at least $24 \mathrm{~h}$ after birth.

The aim of the study was to assess changes in the heart rate, blood pressure and oxygen saturation of hemoglobin during the first $24 \mathrm{~h}$ of life in neonates born after using remifentanil PCA for labor analgesia in comparison with neonates born after labor without any pharmacological analgesia.

\section{Material and methods}

\section{Patients}

The study included 44 infants born at the Department of Obstetrics and Gynecology, and then hospitalized at the Department of Neonatology, Pomeranian Medical University in Szczecin, Poland. All infants were from uncomplicated pregnancies and after a normal spontaneous vaginal delivery.

Enrollment in the study was as follows: Remifentanil PCA for labor was suggested to pregnant women with no known obstetric complications and contraindications to epidural analgesia or in cases when the mother rejected the idea of regional analgesia. Neonates from the mothers who accepted remifentanil analgesia comprised the study group, while neonates from mothers who refused any pharmacological method of analgesia constituted the control group.

Inclusion criteria for the remifentanil group:

- written informed maternal consent for labor analgesia with the remifentanil PCA method obtained before enrollment of the newborn;

- no complications during pregnancy;

- healthy pregnant women;

- term pregnancy. Inclusion criteria for the control group:

- written informed maternal consent for refusal of labor analgesia with remifentanil PCA method obtained before enrollment of the newborn;

- no pharmacological agents of labor pain release used during labor;

- no complications during pregnancy;

- healthy pregnant women;

- term pregnancy.

Exclusion criteria for both groups:

- major congenital malformations (cardiac, central nervous system, respiratory tract, chromosomal abnormalities and all lethal malformations);

- early onset sepsis (recognized up to 72 h of life based on clinical symptoms, laboratory test and bacterial culture results).

The remifentanil group consisted of 23 newborns of mothers who received intravenous remifentanil anesthesia using the method of analgesia controlled by the patient (PCA - patient-controlled analgesia) at the dose of $0.2 \mu \mathrm{g} / \mathrm{kg}$ repeated not more frequently than every 2 min. No background infusions of remifentanil were used. The control group comprised 21 infants born to mothers who did not use any pharmacological forms of anesthesia.

\section{Methods}

The study was designed as a prospective clinical controlled trial, conducted in compliance with the Declaration of Helsinki principles. The protocol and the parental informed consent forms were approved by the institutional review board (Ethical Committee of the Pomeranian Medical University, Szczecin, Poland). Written informed consent of the mother for examinations of the child was obtained in each study case. 
All neonates were observed in the nursery for at least $48 \mathrm{~h}$ after birth with transcutaneous $\mathrm{O}_{2}$ saturation $\left(\mathrm{SCO}_{2}\right)$ monitoring during $24 \mathrm{~h}$ after delivery. Measures of the heart rate (HR) and blood pressure (BP) of the newborns were recorded four times during the first day of life, at 1 h, 6 h, 12 h and 24 h. Vital signs such as the heart rate, transcutaneous $\mathrm{O}_{2}$ saturation of hemoglobin and blood pressure were monitored using a Nellcor Oxi Max monitor N5500 (Tyco Healthcare). Results of measurements of $\mathrm{ScO}_{2}, \mathrm{HR}$ and $\mathrm{BP}$ obtained at $1 \mathrm{~h}, 6 \mathrm{~h}, 12 \mathrm{~h}$ and $24 \mathrm{~h}$ of life were statistically analyzed.

\section{Statistical analysis}

The distribution of continuous variables was tested for normality by the Shapiro-Wilk test. The differences between newborns from the remifentanil PCA labor analgesia group and controls were tested by the Wilcoxon test or Mann-Whitney nonparametric $U$ test as appropriate. Values were presented as mean and standard deviation or median and ranges, as appropriate. A value of $p<0.05$ was considered statistically significant.

\section{Results}

General characteristics of the analyzed groups of newborns are presented in Table I. No significant differences regarding the number of patients enrolled, sex of newborns, gestational age and birth weight between newborns from the compared groups were found (Table I). However, 5-minute Apgar score was significantly lower in the remifentanil than in the control group (Table I).

Five newborns from the remifentanil group (21.7\%) needed respiratory support with an oxygen bag and mask at the delivery room. Three of those demanded an oxygen hood also during the first hours of life, meaning that respiratory depression in newborns can develop after remifentanil used as a PCA method for labor analgesia.

There were no significant differences in $\mathrm{ScO}_{2}$ values recorded at $1 \mathrm{~h}, 6 \mathrm{~h}, 12 \mathrm{~h}$, and $24 \mathrm{~h}$ of life between the compared groups of newborns (Table II).

There was no significant difference in the heart rate (HR) values recorded during the 24-hour monitoring of newborns at $1 \mathrm{~h}, 6 \mathrm{~h}, 12 \mathrm{~h}$, and $24 \mathrm{~h}$ of life between newborns from the compared groups (Table III).

The neonates from the remifentanil group had lower systolic blood pressure in the first hour of life compared to the values found in newborns from the control group but the difference was only on the borderline of statistical significance $(p>0.06)$ (Table IV).

There were no significant differences in the diastolic blood pressure values recorded at $1 \mathrm{~h}, 6 \mathrm{~h}, 12 \mathrm{~h}$,

Table I. General characteristics of participants

\begin{tabular}{|lccc|}
\hline Variable & Remifentanil group & Control group & Statistical analysis \\
\hline Number of patients & 23 & 21 & NS \\
\hline Female sex & $7(30.43 \%)$ & $11(52.38 \%)$ & NS \\
\hline Male sex & $16(69.57 \%)$ & $10(47.62 \%)$ & NS \\
\hline Duration of pregnancy [weeks] & $35-41(39.04 \pm 1.74)$ & $37-41(38.9 \pm 1.28)$ & NS \\
\hline${\text { Birth weight }[g]^{*}}^{*}$ & $2550-4180(3324.8 \pm 443.4)$ & $2400-4000(3366.7 \pm 416.1)$ & NS \\
\hline $5^{\prime}$ Apgar score, median (range) & $9(8-10)$ & $10(9-10)$ & $p<0.001$ \\
\hline
\end{tabular}

*Values are presented as ranges and mean \pm standard deviation

Table II. Comparison of oxygen saturation by pulse oximetry values $\left(\mathrm{ScO}_{2}\right)$ recorded in newborns from the remifentanil and the control group at $1 \mathrm{~h}, 6 \mathrm{~h}, 12 \mathrm{~h}$ and $24 \mathrm{~h}$ of life

\begin{tabular}{|c|c|c|c|c|c|c|c|c|}
\hline Group & Life $[\mathrm{h}]$ & $N$ & Median $\mathrm{ScO}_{2}$ & Minimum $\mathrm{ScO}_{2}$ & Maximum $\mathrm{ScO}_{2}$ & $\mathrm{Q} 25 \%$ & Q75\% & Value of $p^{\star}$ \\
\hline Remifentanil & 1 & 23 & 97.0 & 90 & 100 & 96 & 100 & 0.20796 \\
\hline Control & 1 & 21 & 98.0 & 90 & 100 & 97.5 & 98.5 & \\
\hline Remifentanil & 6 & 23 & 98.0 & 94 & 100 & 96 & 98 & 0.27885 \\
\hline Control & 6 & 21 & 98.0 & 92 & 100 & 97 & 99 & \\
\hline Remifentanil & 12 & 23 & 98.0 & 96 & 100 & 97 & 99 & 0.61449 \\
\hline Control & 12 & 21 & 99.0 & 94 & 100 & 97 & 100 & \\
\hline Remifentanil & 24 & 23 & 98.5 & 96 & 100 & 97 & 100 & 0.86997 \\
\hline Control & 24 & 21 & 98.5 & 96 & 100 & 97.5 & 99.5 & \\
\hline
\end{tabular}

*Statistical analysis - Mann-Whitney $U$ test: differences between groups not significant 
Table III. Comparison of the heart rate (HR) values in beats per minute (bpm) in newborns from the remifentanil and the control group obtained at $1 \mathrm{~h}, 6 \mathrm{~h}, 12 \mathrm{~h}$ and $24 \mathrm{~h}$ of life

\begin{tabular}{|c|c|c|c|c|c|c|c|c|}
\hline Group & Life [h] & $N$ & Median HR [bpm] & Minimum HR [bpm] & Maximum HR [bpm] & Q25\% & Q75\% & Value of $p^{*}$ \\
\hline Remifentanil & 1 & 23 & 138.0 & 127 & 180 & 130 & 149 & 0.54557 \\
\hline Control & 1 & 21 & 142.0 & 130 & 161 & 137 & 145.5 & \\
\hline Remifentanil & 6 & 23 & 138.5 & 103 & 155 & 131 & 142 & 0.26242 \\
\hline Control & 6 & 21 & 140.5 & 122 & 159 & 133.5 & 147 & \\
\hline Remifentanil & 12 & 23 & 136.0 & 110 & 173 & 127 & 148 & 0.60566 \\
\hline Control & 12 & 21 & 138.0 & 118 & 153 & 132 & 145 & \\
\hline Remifentanil & 24 & 23 & 139.0 & 123 & 160 & 134 & 148 & 0.83050 \\
\hline Control & 24 & 21 & 141.0 & 107 & 167 & 135 & 147.5 & \\
\hline
\end{tabular}

*Statistical analysis - Mann-Whitney U test: differences between groups not significant

Table IV. Comparison of systolic blood pressure (SBP) values in newborns from the remifentanil and the control group at $1 \mathrm{~h}, 6 \mathrm{~h}, 12 \mathrm{~h}$ and $24 \mathrm{~h}$ of life

\begin{tabular}{|c|c|c|c|c|c|c|c|c|}
\hline Group & Life $[\mathrm{h}]$ & $N$ & Median SBP & Minimum SBP & Maximum SBP & Q25\% & Q75\% & Value of $p^{\star}$ \\
\hline Remifentanil & 1 & 23 & 59.0 & 49 & 97 & 52 & 67 & 0.06949 \\
\hline Control & 1 & 21 & 68.5 & 36 & 90 & 61 & 76 & \\
\hline Remifentanil & 6 & 23 & 68.0 & 51 & 100 & 54 & 73 & 0.65591 \\
\hline Control & 6 & 21 & 65.0 & 42 & 98 & 60 & 74 & \\
\hline Remifentanil & 12 & 23 & 60.0 & 53 & 81 & 58 & 75 & 0.11315 \\
\hline Control & 12 & 21 & 64.0 & 50 & 93 & 61 & 81 & \\
\hline Remifentanil & 24 & 23 & 66.0 & 41 & 85 & 64 & 72 & 0.89497 \\
\hline Control & 24 & 21 & 64.5 & 52 & 95 & 60 & 76 & \\
\hline
\end{tabular}

*Statistical analysis - Mann-Whitney $\cup$ test: differences between groups not significant

Table V. Comparison of diastolic blood pressure (DBP) values in newborns from the remifentanil and the control group at $1 \mathrm{~h}, 6 \mathrm{~h}, 12 \mathrm{~h}$ and $24 \mathrm{~h}$ of life

\begin{tabular}{|c|c|c|c|c|c|c|c|c|}
\hline Group & Life $[\mathrm{h}]$ & $N$ & Median DBP & Minimum DBP & Maximum DBP & Q25\% & Q75\% & Value of $p^{\star}$ \\
\hline Remifentanil & 1 & 23 & 36.0 & 21 & 56 & 29 & 40 & 0.98683 \\
\hline Control & 1 & 21 & 34.0 & 24 & 55 & 31 & 41 & \\
\hline Remifentanil & 6 & 23 & 38.0 & 23 & 69 & 32 & 41 & 0.31411 \\
\hline Control & 6 & 21 & 32.0 & 20 & 64 & 25 & 50 & \\
\hline Remifentanil & 12 & 23 & 35.0 & 25 & 44 & 32 & 39 & 0.83013 \\
\hline Control & 12 & 21 & 32.0 & 22 & 52 & 30 & 44 & \\
\hline Remifentanil & 24 & 23 & 40.0 & 23 & 67 & 35 & 46 & 0.58605 \\
\hline Control & 24 & 21 & 38.0 & 22 & 53 & 33 & 44 & \\
\hline
\end{tabular}

*Statistical analysis - Mann-Whitney U test: differences between groups not significant

and $24 \mathrm{~h}$ of life between both groups of newborns (Table V).

\section{Discussion}

During childbirth, remifentanil offers hemodynamic stability for the mother, even during general anesthesia, but $50 \%$ of newborns may require ventilatory assistance because of respiratory depression. There is also a case report of generalized rigi- dity and apnea in a neonate immediately after birth following remifentanil administration during caesarean section to a high-risk mother [15]. Therefore, supervision and monitoring of both the mother and the infant are necessary [15].

To the best of our knowledge, this is the first published report on the biophysical monitoring of the heart rate, pulse oximetry and blood pressure during the first $24 \mathrm{~h}$ after birth in neonates born to PCA remifentanil labor analgesia mothers. We found no 
differences in the heart rate, pulse oximetry, or systolic and diastolic blood pressure values between the group of newborns born to remifentanil PCA labor analgesia women and the group of newborns born to control women, except for non-significant hypotension (systolic blood pressure below $60 \mathrm{~mm} \mathrm{Hg}$ in the remifentanil group) at $1 \mathrm{~h}$ after delivery.

Despite a very short half-life in some adult patients, remifentanil was reported to possibly cause side effects even $1 \mathrm{~h}$ after stopping the infusion [16]. Based on the limited number of studies on newborns, one may consider that the varied process of birth (interruption of the mother-fetus metabolism), comorbidities, environmental factors (e.g. maternal smoking, use of medications) and polymorphisms contribute to the individual variability related to the pharmacokinetics of opioids, including remifentanil, in the neonatal period $[6,17]$.

Arnal et al. carried out a systematic review on the use of remifentanil in childbirth analgesia [18]. In the majority of cases, no serious side effects for either mothers or neonates in the delivery room conditions were noted. The authors concluded that intravenous remifentanil may be the drug of choice for childbirth analgesia when regional analgesia techniques are contraindicated [18].

Therefore, in papers published up to now, information about the effects of remifentanil labor analgesia on newborns' vital signs in the first hours after delivery is scarce.

Only in the study of Draisci et al. were neonates observed for at least $24 \mathrm{~h}$ after birth in the nursery, with $\mathrm{SpO}_{2}$ monitoring removed at $3 \mathrm{~h}$ if no episodes of desaturation had occurred [11]. Draisci reported significantly lower Apgar scores at $1 \mathrm{~min}$ and $5 \mathrm{~min}$ after birth and respiratory depression after using remifentanil $0.5 \mu \mathrm{g} / \mathrm{kg}$ as a bolus in cesarean section under general anesthesia [11]. They concluded that even at low doses remifentanil has the potential to cause respiratory depression. No other adverse effects during the first $24 \mathrm{~h}$ of neonatal life were observed in their study [11].

The ideal regimen for remifentanil infusion is yet to be established and further studies on maternal and fetal safety need to be carried out. During our study project, the dose of $0.2 \mathrm{\mu g} / \mathrm{kg}$ repeated not more frequently than every 2 min with no background infusion of remifentanil was used. Such doses seem to be safe from the fetal/neonatal point of view [4]. Additional information about the doses safe for neonates may be found in reports on the use of remifentanil in neonatal intensive care and anesthetic practice [6]. Lago et al. recorded the number of clinically significant desaturations, apnea and hypotension for the first $3 \mathrm{~h}$ after the infusion of remifentanil $0.03 \mu \mathrm{g} / \mathrm{kg} / \mathrm{min}$ was over [1].

In a study by Wee et al., the starting rate of $0.025 \mu \mathrm{g} / \mathrm{kg} / \mathrm{min}$ was considered preferable to avoid bradycardia and hypotension that were observed after administration of either a bolus of $1 \mu \mathrm{g} / \mathrm{kg}$ or an infusion rate of $1 \mu \mathrm{g} / \mathrm{kg} / \mathrm{min}$ [19]. In a doubleblinded, randomized and prospective study of Chambers, clinically insignificant bradycardia and mild hypotension (with no repercussion on peripheral perfusion) frequently followed administration of remifentanil $1 \mu \mathrm{g} / \mathrm{kg} / \mathrm{min}$ or saline as a bolus over 1 min [20].

Davis et al., and Galinkin et al., among 60 patients with a mean rate of remifentanil infusion of $0.55 \mu \mathrm{g} / \mathrm{kg} / \mathrm{min}$, noticed the necessity of hypotensive treatment (systolic blood pressure $<60 \mathrm{~mm} \mathrm{Hg}$ ) in $11 \%$ of the patients [2, 3].

In a pilot study, INSURE, with remifentanil $2 \mu \mathrm{g} / \mathrm{kg}$ infused over $60 \mathrm{~s}$, mean blood pressure decreased 5 min after remifentanil application, and usually normalized within 20-30 min after remifentanil infusion [21]. Hypothetically, remifentanil PCA labor analgesia may negatively influence the newborn condition even up to $30 \mathrm{~min}$ after birth. It should also be taken into account that higher remifentanil doses are associated with an increased risk of side effects. In the year 2010, Standing et al., published a study about the relationship between whole blood remifentanil concentration and its hypotensive effects in infants undergoing cranioplasty [22]. They concluded that remifentanil is effective in causing arterial hypotension.

Summarizing the above data and our results, hypotension after remifentanil infusion can occur. Further trials are needed to evaluate ideal dosing regimens and combinations of agents to be used with remifentanil in labor analgesia.

Our study has some limitations, chief among them the studied problem itself, whether or not to give labor analgesia. From an ethical point of view, a randomized, blinded study of used or not used labor analgesia is not accepted in pregnant women during labor. Also, it is commonly known that some pregnant women prefer to have natural labor without any pharmacological analgesia. Therefore, in our study the choice of whether to use labor analgesia or refuse it belonged to the mother and not to the researcher.

Secondly, the total dose of remifentanil varied depending on the length of labor and the number of applications provided by the mother. In the remifentanil-PCA method minimum interval between doses on the level of 2 min was specified, but the actual interval between successive doses in the method of PCA was dependent on the subjective perception of pain by the women giving birth. The time from the last dose of remifentanil to the moment of delivering the baby was also different, but in each case was longer than the half-life time of remifentanil. Taking into account that remifentanil has a very short halflife time, the listed limitations should not have any significant influence on our results and conclusions. 
In conclusion, remifentanil PCA analgesia during labor in doses of $0.2 \mu \mathrm{g} / \mathrm{kg}$, repeated not more frequently than every $2 \mathrm{~min}$, does not significantly modify the hemoglobin oxygen saturation, heart rate and blood pressure in infants during the first day of life. Further studies are needed to explain the observed trend for arterial hypotension in the first hour of life in infants born to mothers treated with remifentanil.

\section{References}

1. Lago P, Tiozzo C, Boccuzzo G, Allegro A, Zacchello F. Remifentanil for percutaneous intravenous central catheter placement in preterm infant: a randomized controlled trial. Paediatr Anaesth 2008; 18: 736-44.

2. Davis PJ, Galinkin J, McGowan FX, et al. A randomized multicenter study of remifentanil compared with halothane in neonates and infants undergoing pyloromyotomy. I. Emergence and recovery profiles. Anesth Analg 2001; 93 : 1380-6.

3. Galinkin JL, Davis PJ, McGowan FX, et al. A randomized multicenter study of remifentanil compared with halothane in neonates and infants undergoing pyloromyotomy. II. Perioperative breathing patterns in neonates and infants with pyloric stenosis. Anesth Analg 2001; 93: 1387-92.

4. Kranke P, Schelling P, Frambach T, Wirbelauer J. Remifentanil-PCA to alleviate labor-pain - a true and safe alternative to epidural labor analgesia? Anasthesiol Intensivmed Notfallmed Schmerzther 2009; 44: 660-3.

5. Kan RE, Hughes SC, Rosen MA, Kessin C, Preston PG, Lobo EP. Intravenous remifentanil: placental transfer, maternal and neonatal effects. Anesthesiology 1998; 88: 1467-74.

6. Penido MG, Garra R, Sammartino M, Pereira e Silva Y. Remifentanil in neonatal intensive care and anaesthesia practice. Acta Paediatr 2010; 99: 1454-63.

7. Allegaert K, Simons SH, Vanhole C, Tibboel D. Developmental pharmacokinetics of opioids in neonates. J Opioid Manag 2007; 3: 59-64.

8. Bouattour L, Ben Amar H, Bouali Y, et al. Maternal and neonatal effects of remifentanil for general anaesthesia for Caesarean delivery. Ann Fr Anesth Reanim 2007; 26: 299-304.

9. Ngan Kee WD, Khaw KS, Ma KC, Wong AS, Lee BB, Ng FF. Maternal and neonatal effects of remifentanil at induction of general anesthesia for cesarean delivery: a randomized, double-blind, controlled trial. Anesthesiology 2006; 104: 14-20.

10. Palacio FJ, Ortiz-Gómez JR, Fornet I, López MA, Morillas P. Remifentanil bolus for cesarean section in high-risk patients: study of 12 cases. Rev Esp Anestesiol Reanim 2008; 55: 86-9.

11. Draisci G, Valente A, Suppa E, et al. Remifentanil for cesarean section under general anesthesia: effects on maternal stress hormone secretion and neonatal well-being: a randomized trial. Int J Obstet Anesth 2008; 17: 130-6.

12. Volikas I, Butwick A, Wilkinson C, Pleming A, Nicholson G. Maternal and neonatal side-effects of remifentanil patientcontrolled analgesia in labour. $\mathrm{Br} J$ Anaesth 2005; 95: 504-9.

13. Blair JM, Dobson GT, Hill DA, McCracken GR, Fee JP. Patient controlled analgesia for labour: a comparison of remifentanil with pethidine. Anaesthesia 2005; 60: 22-7.

14. Jaskot B, Czeszyńska MB, Konefał H, Pastuszka J. Method of analgesia for labor in relation to newborn condition, cord blood cortisol and interleukin-6 levels [Polish]. Ginekol Pol 2011; 82: 767-74.
15. Hill D. Remifentanil in obstetrics. Curr Opin Anaesthesiol 2008; 21: 270-4.

16. Knapik M, Misiołek H, Knapik P, Dyaczyńska-Herman A. Remifentanil - ultra-short acting opioid and its possible applications in anesthesiology [Polish]. Wiad Lek 2005; 58: 353-7.

17. Stefano GB, Kream RM. Opioid peptides and opiate alkaloids in immunoregulatory processes. Arch Med Sci 2010; 6: 456-60.

18. Arnal D, Serrano ML, Corral EM, García del Valle S. Intravenous remifentanyl for labor analgesia. Rev Esp Anestesiol Reanim 2009; 56: 222-31.

19. Wee LH, Moriarty A, Cranston A, Bagshaw O. Remifentanil infusion for major abdominal surgery in small infants. Paediatr Anaesth 1999; 9: 415-8.

20. Chambers N, Lopez T, Thomas J, James MF. Remifentanil and the tunnelling phase of paediatric ventriculoperitoneal shunt insertion. A double-blind, randomised, prospective study. Anaesthesia 2002; 57: 133-9.

21. Welzing L, Kribs A, Huenseler C, Eifinger F, Mehler K, Roth B. Remifentanil for INSURE in preterm infants: a pilot study for evaluation of efficacy and safety aspects. Acta Paediatr 2009; 98: 1416-20.

22. Standing JF, Hammer GB, Sam WJ, Drover DR. Pharmacokinetic-pharmacodynamic modeling of the hypotensive effect of remifentanil in infants undergoing cranioplasty. Paediatr Anaesth 2010; 20: 7-18. 